\title{
Los límites (¿necesarios?) del expansionismo romano en etapa altoimperial: El sueño de Druso
}

\author{
The limits (necessary) of roman expansion in stage high- \\ imperial: The Druso's dream
}

\author{
Eduardo Pitillas Salañer*
}

\begin{abstract}
RESUMEN
ABSTRACT

La expansión romana en etapa altoimperial atravesó momentos diversos, unos de impulso, otros de contención de la ya conquistado. Esta dinámica aparece configurada por las propias circunstancias de cada momento y por la determinación (o carencia de ella) de cada emperador reinante. El sueño de Druso (padre del emperador Claudio), asunto que supera la simple valoración de anécdota para convertirse en llamada de atención, sirve de referencia textual a la hora de valorar

tal dinámica.

PALABRAS CLAVE:

Expansionismo, contención e impulso, límite, civilización-barbarie, pompa (fasto), revueltas, postconquista.

The Roman expansion in stage highimperial crossed diverse moments, some of impulse, others of containment of the already conquered thing. This dynamics turns out to be formed by the proper circumstances of every moment and for the determination (or lack of it) of every reigning emperor. The Druso's dream (father of the emperor Claudio), matter that overcomes the simple valuation of anecdote to turn into warning, uses as textual reference at the moment of valuing such a dynamics.

KEYWORDS:

Expansionism, containment and impulse, limit, civilization-barbarism, ostentation, revolts, post-conquest.
\end{abstract}

* Dr. Historia Antigua. Camilo Alonso Vega 48, Portal 1, 1ํ A. 39005 Santander. IES Augusto González de Linares (Santander). E-mail: ug-hematología@ humv.es 
[Is Drusus in quaesturae praeturaeque honore dux Raetici, deinde Germanici belli Oceanum septemtrionalem primus Romanorum ducum nauigauit transque Rhenum fossas naui et immensi operis effecit, quae nunc adhunc Drusinae uocantur. Hostem etiam frequenter caesum ac penitus in intimas solitudines actum non prius destitit insequi, quam species barbarae mulieris humana amplior uictorem tendere ultra sermone Latino prohibuisset.] [Druso durante su cuestura y su pretura tuvo un mando en la guerra de Recia y en la de Germania, siendo el primer general romano que navegó por el océano septentrional. Hizo abrir al otro lado del Rin canales de nueva forma y gran extensión, que aún hoy se llaman Drusinas. Inflingió frecuentes derrotas al enemigo, rechazándole hasta sus bosques, y dejó sólo de perseguirle el día en el que se presentó una mujer de aquella nación de estatura más que humana, la cual hablándole en latín, le prohibió que llevase más adelante sus victorias (Suetonio, Divus Claudius, 1, 2-3)].

¿Debe crecer un imperio - en el supuesto de que tal fórmula expansiva sea tenida por modelo a imitar y políticamente correcta- hasta el límite de sus posibilidades o, por el contrario, debe medir adecuadamente, con prudencia, su capacidad real de expansión para evitar sucumbir a posteriori y desmoronarse cual coloso de pies de barro?

Si pensamos en el caso romano y analizamos la dinámica de su crecimiento, una vez ya configurado el imperium en época de la tardía república, cabría preguntarse: ¿Cómo prosiguió ese crecimiento? ¿Existió algún tipo de proyecto o de iniciativa calculada? ¿Se frenó, en algún momento, el expansionismo pensando que había llegado al límite de sus posibilidades reales?

El imperio romano pudo haberse debatido entre la utopía de la expansión sin limitación alguna (dominium mundi), —una herencia de Alejandro y que se plasma en la Eneida de Virgilio1- y la realidad cotidiana de unos límites que eran necesarios $^{2}$, bien como referencia de hasta dónde se puede llegar en un momento determinado, bien como espacio que es preciso organizar, en su círculo más in-

1 A. Montenegro Duque, «La política de estado universal en César y Augusto a través de la Eneida de Virgilio», REP, XXXIII, 1950, 57-97. R. Olmo López, «La idea imperial en Virgilio», ETF, Serie II, Historia Antigua, 21, 2008, 259-273.

2 M.J. Hidalgo de la Vega, «Ecumenismo romano: entre utopía y realidad», Stud. hist., $\mathrm{H}^{\mathrm{a}}$ antig., 26, $2008,47-62$.

3 N. Terrenato, «Las implicaciones culturales de la conquista romana», Europa Romana, Barcelona, 2009, 267 y ss, (vid., mapa 8.1. , 269). 
terno, frente al más periférico y externo ${ }^{3}$. Ello no impide - todo lo contrario- que la influencia llegue lejos, a docenas de kilómetros, a través de la difusión comercial.

En principio, podría pensarse que cualquier fenómeno expansivo es limitado (y no solo porque el orbe lo sea). Se diría que la incapacidad para entender este presupuesto puede conducir al desastre y en el caso de una guerra a la derrota. Si la política se ha de interpretar en términos pragmáticos, como ejercicio de realismo, no faltan ejemplos contrarios, por otro lado recientes. El III Reich ${ }^{4}$ y el liderazgo mesiánico de Hitler ${ }^{5}$ es modelo de despropósito, en el que el jerarca nazi, acostumbrado al riesgo absoluto, consigue alcanzar —al final- (aunque inicialmente ése no fuera su deseo) la destrucción y la auto-inmolación antes que el éxito, en una empresa que, destinada utópicamente a largo plazo (el milenio nazi), cronológicamente sólo recorrería una reducidísima parte (algo más de una década, tan sólo trece años [1933-1945]), del proyecto inicialmente trazado.

Cualquier comparación entre el expansionismo romano y el del régimen nacionalsocialista está fuera de lugar. En principio, porque dos mil años separan ambos fenómenos. Luego, porque en nada es comparable el dirigente alemán (que un integrante del Estado del Vaticano ${ }^{6}$ calificara sarcásticamente como Atila motorizado) con la labor continuada — no exenta de avances y detenciones- de los emperadores romanos, aunque éstos, en momentos puntuales, se hayan visto también arrastrados como el caudillo totalitario, por la locura ${ }^{7}$ o el capricho del poder.

El expansionismo romano, lejos de fundamentarse en la exclusión y el racismo (fenómeno en sentido estricto desconocido en la Antigüedad), se apoyó, por el contrario, en la capacidad de absorción e integración. Así Roma crecía, al crecer, a su vez, su capacidad de imitación, lo que ha llevado a algunos, a mi entender equivocada y excesivamente, a restarle originalidad e importancia, y atribuírsela, por entero, a los bárbaros ${ }^{8}$. Y aunque es evidente que la cuestión civilización versus barbarie responde a arquetipos y que los historiadores grecorromanos aportaron, en buena medida, una visión estereotipada de las costumbres de los otros, no se ha de infravalorar, por ello, la labor organizativa y asimiladora del mundo romano, aunque fuera como modelo no consciente. La cuestión de la integración ${ }^{9}$, aunque quizá deba rebajarse en términos absolutos no, por ello, dejó de ser empresa de gran envergadura, puesta en práctica de un fenómeno que comenzó a experimentarse, grosso modo, durante el helenismo,

4 R. J. Evans, El Tercer Reich en el poder, 1933-1939, Barcelona, 2007.

5 Vid., preferentemente: A. Bullock, Hitler, Barcelona, 1969. J. C. Fest., Hitler, 2 vols., Barcelona, 1974. I. Kershaw, Hitler, 2 vols., Barcelona, 2000.

6 J. Cornwell, El Papa de Hitler. La verdadera historia de Pío XII, Barcelona, 2001.

7 T. Mommsen, El mundo de los Césares, México, 1945. R. F. Martín, Los doce Césares. Del mito a la realidad, Madrid, 1998. J.M. Roldán, Césares, Madrid, 2008. VV.AA., Vidas de los césares, Anthony A. Barrett, ed., Barcelona, 2009.

8 T. Jones y A. Ereira, Roma y los bárbaros. Una historia alternativa, Barcelona, 2008.

9 VV.AA., Formas de integración en el mundo romano, Madrid, 2009. 
y que en todo caso mostró el éxito de Roma (la Urbs), allí donde anteriormente habían fracasado las poleis griegas.

Volviendo a la idea inicial de los límites viene a cuento aquí la anécdota (¿o quizá no lo sea tanto?) que nos transmite Suetonio a propósito del sueño de Druso ${ }^{10}$ : Una mujer se le apareció haciéndole ver la inconveniencia de seguir su aventura germana. ¿Era una advertencia para que Roma midiera adecuadamente sus posibilidades expansivas?

Esa «advertencia» parece que fue considerada cuando, años más tarde, Augusto, tras el desastre del saltus Teutoburgiensis $(9 \text { d. C. })^{11}$, ya en sus últimos años (Augusto fallece el $14 \mathrm{~d}$. C.) pudo haber recomendado a Tiberio, su sucesor, que se limitara a mantener lo conquistado. Tiberio, que había sido, a diferencia de Augusto, un buen general y que había estado al frente de sendas campañas en Germania y el llírico, y que tenía ya una cierta edad (contaba con cincuenta y seis años cuando toma la púrpura imperial), decidió, de buen grado, seguir el consejo del emperador. Metódico y ahorrativo prefirió echar cuentas de los gastos militares y forzó a Germánico (hijo de Druso) a desistir de más empresas «gloriosas», asunto que pudo enturbiar las relaciones entre tío y sobrino (aunque no hasta el punto como se ha pretendido) y llegar a forjar intencionadamente dos arquetipos historiográficos: el del héroe (Germánico) frente al del antihéroe (Tiberio) ${ }^{12}$.

El poder se expresa también en términos de límites ${ }^{13}$. Esa toma de conciencia ${ }^{14}$ es importante porque además, en el caso romano, no se trata únicamente de un límite fronterizo ${ }^{15}$ (frente a las externae gentes), de aquellos que se sitúan fuera sino que a los de dentro (los intraliminares ${ }^{16}$ ), es preciso igualmente sujetar. Así, muchas de las pruebas de fuerza que legiones romanas y cuerpos auxiliares llevaban a cabo en las fronteras constituía, especialmente, un modo de mostrar autoridad hacia los situados en el interior del Imperio.

10 Suet., Claudio, 1, 2-3. E. Pitillas Salañer, Roma. La forja de un imperio, Zaragoza, 2010, 15. Casio Dión (LIV, 1,3) transmite una anécdota semejante [Le había salido al encuentro una mujer de estatura mayor que la humana y le había dicho: “¿Adónde vas tan corriendo, insaciable Druso? No te está concedido ver todo esto. ;Vuélvete! Ha llegado el final de tus hazañas y de tu vida»]: K. Bringmann, Augusto, Barcelona, 2008, 203.

${ }^{11}$ E. Pitillas Salañer, «Tiberio y los germanos», Homenaje al Profesor Montenegro. Estudios de Historia Antigua, Valladolid, 1999, 400-402.

12 J. Mangas Manjares, «Germánico y Tiberio», Héroes y antihéroes en la Antigüedad clásica, Madrid, 1997, 295-313.

13 F.J. Guzmán Armario, «¿El poder de los límites o los límites del poder?: reflexiones sobre las fronteras del mundo romano», Revista atlántico-mediterránea de prehistoria y arqueología social, 4, 2001, 285-304.

14 En torno a esa toma de conciencia de haber alcanzado los límites naturales: R. Chevallier, Rome et la Germanie au ler. siècle de notre ère, Latomus, LIII, Bruselas, 1961, 25-26 y 45.

15 Con todas las salvedades que encierra todo limes entendido también como proyección y área de contacto con el mundo exterior.

16 F.J. Guzmán Armario, Romanos y bárbaros en las fronteras del Imperio Romano según el testimonio de Amiano Marcelino, Madrid, 2006, 95 y ss. 
Roma se había convertido en potencia hegemónica, sin rival, cuando perdió el miedo a los galos ${ }^{17}$ (aunque es posible que luego lo sustituyera por el miedo a los germanos) y, sobre todo, cuando, con su proverbial tenacidad hizo frente con éxito a Aníbal Barca ${ }^{18}$ en la Segunda Guerra Púnica (218-201 a. C. $)^{19}$. Entonces Roma se forjó como imperio.

El expansionismo romano fue una idea desplegada dentro de las posibilidades reales de cada momento ${ }^{20}$. Ningún imperio, ni en la Antigüedad ni en épocas recientes, se ha planificado de antemano. Tal tarea se labra a tenor de las circunstancias de cada momento y el guión se escribe después.

La conquista de Hispania por Roma (218-19/16 a. C. $)^{21}$ fue un proceso largo, dilatado en extremo, y sólo se comprende en función de ritmos discontinuos ${ }^{22}$ y secuencias no bien enlazadas. Otros escenarios y otras preocupaciones, amén de una meseta interior inhóspita y la falta de motivación económica (junto a la propia actitud no exenta de belicosidad de los indígenas) pudieron provocar esos avances y detenciones, ese ritmo impreciso pero - en ocasiones - cansino y tedioso. Nada comparables a la rápida (y brutal) conquista de la Galia por César, expresión, de una ambición personal del, en palabras del prestigioso Luciano Canfora $^{23}$, dictador democrático.

Augusto, el sobrino-nieto de César, es el creador del Imperio, entendido como estructura de poder institucionalizada en torno a la figura del nuevo Princeps. Su guerra contra cántabros y astures (29-19/16 a. C.) constituye un buen ejemplo de una campaña de prestigio, encaminada especialmente a cauterizar las profundas heridas del último enfrentamiento civil, que concluye en Actium (31 a. C.) sobre la flota conjunta romano-egipcia [Marco Antonio y Cleopatra (VII)]. La definitiva ocupación del Norte y del Noroeste de Hispania conlleva el final del largo proceso de conquista y resistencia que, para determinado investigador, ha tenido una lectura diplomática ${ }^{24}$, y no sólo bélica. Sea como fuere, una vez concluida la guerra contra los pueblos del norte, la consiguiente ocupación militar ${ }^{25}$ facilita el contacto con las

17 En la batalla de Telamón (225 a. C.): F. Gracia Alonso, Furor barbari! Celtas y germanos contra Roma (s. IV a. C-I d. C.), Barcelona, 2009, 86.

18 S. Lancel, Aníbal, Barcelona, 1997. G. Brizzi, Escipión y Aníbal. La guerra para salvar a Roma, Barcelona, 2009.

19 A. Goldsworthy, La caída de Cartago. Las Guerras Púnicas, 265-146 a. C., Barcelona, 2008, 169386.

20 E. Pitillas Salañer, Roma. La forja de un imperio, Zaragoza, 2010, 11-15.

21 Para un análisis del papel del ejército romano en la conquista vid., F. Cadiou, Hibera in terra miles. Les armées romaines et la conquête de l'Hispanie sous la République (218- 45 av. J.-C.). Madrid, 2008.

22 J.M. Roldán Hervás, «Impulsos políticos de la Conquista de Hispania en el siglo II a. C.», Homenaje a M. Vigil Pascual, Sevilla, 1994, 475-486.

23 Julio César. Un dictador democrático, Barcelona, 2000. 2002.

${ }^{24}$ E. García Riaza, Celtíberos y lusitanos frente a Roma: diplomacia y derecho de guerra, Vitoria ,

25 N. Santos Yanguas, Militares astures en el ejército romano, Aqvila Legionis, 13, Madrid, 2010, 48 y ss. 
poblaciones indígenas ${ }^{26} \mathrm{y}$, a la larga, hace posible la participación de auxiliares galaicos y astures ${ }^{27}$ en el seno del ejército romano. Todo ello conlleva, a buen seguro, una idea de promoción que se refleja en la adquisición del derecho de ciudadanía como colofón a un prolongado servicio militar de veinticinco años.

Augusto no necesitó utilizar la propaganda a diferencia de los regímenes totalitarios del siglo XX. Su arte ${ }^{28}$ es expresión de pompa, de fasto monárquico, como fórmula natural del propio poder imperial. Los dictadores del siglo XX, por el contrario, necesitaron de la propaganda para afianzar su liderazgo y convertirse así en jefes ${ }^{29}$.

El primer emperador sentó los fundamentos de una sociedad neoconservadora, respetuosa con la moral tradicional y las costumbres de los antepasados, y todo ello para asentar (salvadas las distancias con el mundo actual) una determinada identidad «nacional». Para ello se sirvió de la épica y de la analística romanas (Virgilio y Livio). Y una vez consolidada la ocupación de sendos territorios (norte de Hispania, Alpes Occidentales, Marítimos y Cotios, control administrativo de la Galia, avance en Germania...) recurre también a los reyesclientes, como es el caso de Herodes el Grande, su gran valedor en Judea. Su muerte (4 a. C.) destapa la inestabilidad, y muestra hasta qué punto el idumeo (nunca tenido por auténtico judío por sus connacionales) era rechazado por algunas facciones religiosas, especialmente los fariseos. Años más tarde (6 d. C.), con el censo de Quirino, aflora - a decir de Flavio Josefo- una nueva corriente radical, la «cuarta filosofía». Se inicia así en aquella parte del imperio, con altibajos, la trayectoria de una oposición al poder romano, que estallará posteriormente y en toda su virulencia, en el $66 \mathrm{~d}$. C.

Si el legado de Siria, Publio Quintilio Varo, acabó con éxito la revuelta que se origina a la muerte de Herodes, su incompetencia se mostró, años más tarde en

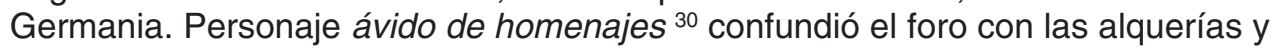
bosques de una tierra hostil, en vías de incierta asimilación. Los guerreros de Arminio $^{31}$, al acecho, destruyeron un ejército de 20.000 hombres en Teutoburgo. Aquel desenlace fatal que desesperó a Augusto, según Suetonio ${ }^{32}$, no tuvo arreglo. La aventura en Germania, que nada bueno presagiaba poco antes con la caída

${ }^{26}$ E. Pitillas Salañer, «Función integradora del ejército romano de ocupación en tierras del norte y del noroeste de Hispania durante la etapa de postconquista», HAnt., XXXI, 2007, 111-126.

${ }_{27}$ Id., "Soldados auxiliares del ejército romano originarios del NW de Hispania (s. I d. C.)», HAnt., XXX, 2006, 21-34.

28 P. Zanker, Augusto y el poder de las imágenes, Madrid, 1992.

29 «...se ha creído encontrar una clave para los siglos antiguos en la propaganda de las terribles dictaduras del siglo XX. Era como tomar un montículo por el Mont Blanc: aquellas formidables empresas, las de un Goebbels, las Juventudes hitlerianas y mussolinianas, el "culto a la personalidad" estaliniano, más la policía secreta y las denuncias anónimas, no tenían nada en común con el fasto pomposo, anodino y automático de las viejas monarquías...»: P. Veyne, El imperio grecorromano, Madrid, 2009, 337.

${ }_{30}$ Según expresión tomada de L. Harmand, L'Occident Romain. Gaule, Espagne, Bretagne, Afrique du Nord (31 av. J.-C.-236 apr. J.C.), París, 1969, 87.

31 D. Timpe, Arminius-Studien, Heidelberg, 1970. Arminius: RE, II-1, 1190-1200.

32 «Quintili Vare, legiones redde!» Suet., Aug., 23, 2. 
desde el caballo de $\operatorname{Druso}^{33}$ (9 a. C.), tierra cruel e inhóspita ${ }^{34}$, arquetipo del barbaricum, se había «tragado» no sólo a un buen general (aunque fuera por accidente $)^{35}$ sino, en mayor medida, a un legado incompetente y a sus tropas. El resultado estaba cantado; había que renunciar al Elba como límite fluvial y conformarse con el Rin, antiguo curso que, según César, separaba galos de germanos. Se convertía en realidad el sueño de Druso; no era conveniente avanzar más y por haberlo intentado aquella empresa habría fracasado (?). Así lo entendió Augusto y quizá así se lo transmitiera también a Tiberio (?).

El nuevo emperador, entrado en años, no estaba ya para aventuras de juventud. Su carácter ${ }^{36}$ reservado y desconfiado ${ }^{37}$; su, por otro lado, gran virtud (se trataba de un personaje, a su vez, metódico, organizado y ahorrativo, ¿lindando lo tacaño?) pronto le hizo ver que Roma debía evitar sobreesfuerzos y que, por lo

33 Drusus lulius Caesar. K-RE, 5, 170-171. Campañas de Druso (D. Cass., LV, 1-2.): la primera expedición, llevada a cabo durante la primavera del 12 a. C., ya tenía como objetivo la intimidación de los germanos y alejarlos del cauce del Rin. Al finalizar el verano de aquel mismo año, Druso toma contacto con la costa frisona y explora el curso del Lippe. En la campaña siguiente (11 a. C.), tras atravesar el territorio de usipetes, sicambri y cherusci, alcanza el río Visurgo (Weser). En el año 9 a. de C. invade el país de los chatti. Atraviesa el Weser, posiblemente por segunda vez, y se dirige al Elba. Un hecho desafortunado paraliza las operaciones militares. Su caballo, al caer y rodar sobre él, le parte el fémur. Fallece en el mes de septiembre de aquel mismo año (A.A. Barrett, Livia. Primera dama de la Roma imperial, Madrid, 2004, 77). La muerte de Druso tuvo que deberse a una infección generalizada, una septicemia (R.F. Martín, Los doce Césares. Del mito a la realidad, Madrid, 62) ya que el ejército romano contaba con equipos médicos y capacidad sanitaria (hospital militar: valetudinarium; Castra VeteraXanten) suficiente como para solventar una caída desde el caballo (A. Everitt, Augusto. El primer emperador, Barcelona, 2008, 324). Druso fallece a los treinta días de producirse la infortunada caída (K. Bringmann, Augusto, Barcelona, 2008, 203).

34 Ovidio, Pont., II, 8, 35-50.

35 Las cosas no parecían pintar bien en Germania como parece reflejar en la anécdota del enjambre de abejas [Obs. 72]: Julio Obsecuente, Libro de los Prodigios, Madrid, 1990.

${ }_{36}$ Su falta de comunicación y su incapacidad para asumir su auténtico papel de emperador según J.M. Roldán (Césares, Madrid, 2008, 190).

${ }_{37}$ Se ha de tener cuidado en no polarizar en exceso la imagen que, a simple vista, traza Tácito del emperador como dinasta taciturno, desconfiado, excesivamente reservado, calculador e impopular. Esa imagen deformante de Tiberio podría haber tenido su origen en determinadas fuentes utilizadas por Tácito: las perdidas Memorias de Agripina la Joven, hija de Germánico y madre de Nerón y las, también perdidas, Guerras de Germania de Plinio el Viejo. A ello contribuirían igualmente la influencia de dos historiadores (Servilius Nonianus y Aufidius Bassus). Tácito recoge, por lo tanto, una tradición claramente hostil hacia el emperador: vid., A. Michel, Tacite et le destin de l'empire, París, 1966. Pero, aún teniendo en cuenta lo anteriormente señalado, tampoco se ha de extrapolar el estilo elocuente de Tácito con una pretendida y supuesta falta a la verdad de este historiador. La contraposición Germánico (héroe)-Tiberio (antihéroe) puede llevar a cierto extremo interpretativo, que quizá convenga corregir. La generosidad, afabilidad, lealtad, energía, espíritu de conquista y popularidad de Germánico parecen contrastar, a simple vista, con la misantropía del emperador y su tendencia al disimulo. El problema interpretativo puede estar en el complejo cuadro histórico, de caracteres, de sospechas, rumores, dimes y diretes, que presenta el historiador. Una lectura más atenta de Tácito permite distinguir entre las opiniones de los demás, contradictorias entre sí (como es lógico, y que Tácito recoge en su perfil social más variopinto) y lo que el propio historiador opina, mucho más mesurado y cauteloso esto último. El modo de hacer histórico de Tácito responde a una composición dramática en el que atiende la psicología de los personajes, en la muestra de sus pareceres y en la no menos interesante creación de un determinado clima. De ahí que estos aspectos se han de tener en cuenta para no caer en un exceso de deformación del personaje (Tiberio) o una interpretación abusiva del historiador por lo que parece necesario distinguir entre lo que dicen sus protagonistas, que el historiador recoge y lo que él directamente opina: $\mathrm{E}$. Aubrin, «L eloquentia de Tacite et sa fides d'historien», ANRW, II, 33.4, 1991, 2598-2688. 
tanto, era preferible utilizar la diplomacia a la guerra. Así se lo plantea a Germánico quien, en su campaña de expiación patriótica habría buscado, tras descubrir con espanto las osamentas ${ }^{38}$ de los caídos en el saltus Teutoburgiensis y contemplar el rastro de los milites sacrificados en los altares bárbaros, un resultado definitivo frente al caudillo querusco. Pero una victoria que se escapaba de la manos - por lo tanto, costosa- no entraba en los cálculos del emperador, su tío. Así que Germánico, más bien obligado, regresó a Roma.

Tiberio dejó a los germanos a su suerte y en ello acertó. Sus rivalidades hicieron el resto. Arminio sucumbió bajo la espada de sus propios paisanos ${ }^{39}$. Germania no era únicamente cruel con los romanos.

Con Tiberio asistimos al comienzo de una serie de revueltas de postconquista ${ }^{40}$, que tuvieron su origen en descontentos de naturaleza fiscal, en algún caso como rechazo a levas indígenas, o bien como reacción frente a una asimilación escasamente consolidada, y que se manifestaron de modo casi simultáneo entre el 17 y el 26 d. C. ${ }^{41}$. Este tipo de respuestas indígenas, aunque abocadas al fracaso, no por ello dejaran de ser molestas para el poder imperial. El reinado de Tiberio supone, por lo tanto, el afianzamiento de lo ya conquistado en época de Augusto (aunque estas conquistas augústeas fueran obra de sus generales, entre los que destacaron su yerno M. Vipsanio Agripa y el propio Tiberio). Si César, en las postrimerías de la república, sentó los fundamentos de algo que institucionalizaría su sucesor Augusto, con Tiberio se consolidaron los límites previamente alcanzados. De ahí que a un periodo de expansión, siguiera otro de consolidación marcándose así, en cada momento y desde una base realista, los límites - siempre provisionales- del Imperio. Era ésta una forma de optimizar el consejo dado a Druso. Y todo ello contando con el apoyo, imprescindible, de las elites locales que servían de soporte al proceso de autoromanización ${ }^{42}$.

Con Calígula no hubo tiempo para nada, y no solo por la corta duración de su reinado (37-41 d. C.), sino más bien porque no parecía estar en el ánimo del nuevo purpurado seguir la tradición militar ni del padre (Germánico), ni del tíoabuelo (Tiberio) ${ }^{43}$. Su teatral puesta en escena en el Canal de la Mancha frente

\footnotetext{
38 Tac., Ann., I, 61, 2-3.

39 Asesinado por sus propios connacionales, previamente había escapado a un envenenamiento de Adgandestrius, caudillo de los chatti, según un rumor recogido por Tácito: Ann., II, 63, 6.

40 S.L. Dyson, «Native Revolt Patterns in the Roman Empire», ANRW, II, 3, 1975, 138-175. E. Pitillas Salañer, "Los "nacionalismos" en el imperio y su resistencia a la asimilación romana. Estudio de las fuentes», HAnt., XIX, 1995, 255-279.

41 E. Pitillas Salañer, «Levantamientos en la Galia, África y Tracia durante el reinado de Tiberio», HAnt., XX, 1996, 137-148.

42 Frente al más clásico término de romanización, se barajan otros como el de asimilación, integración, etc. No obstante, nada de esto se comprende si no se tiene en cuenta la voluntad de los propios pueblos sometidos, quienes en un momento determinado, contando con el apoyo inestimable de sus aristocracias, se vinculan al mundo romano, de motu propio.

43 A pesar de que se había educado en los campamentos y llevaba respondía al apodo de «botitas» (caligae, Calígula).
} 
a Britannia ${ }^{44}$, no deja de ser un hecho extraño (¿e histriónico?), frustrado anticipo de la conquista que llevaría a cabo posteriormente, con indudable éxito (por lo menos como empresa por él dirigida), el emperador Claudio, su tío, y ello a pesar de sus conocidas taras y deficiencias neurológicas ${ }^{45}$. Así, a unos años de gastos superfluos del emperador Calígula ${ }^{46}$ (aprovechando los fondos recogidos por su antecesor Tiberio), siguieron otros de nueva actividad expansiva, plasmada en la ocupación de Britania (43 d. C.) ${ }^{47}$, empresa que se había ido relegando, por unos u otros motivos, desde época de Augusto.

Bajo Nerón estalla en la isla la revuelta de Boudicca (61 d. C.), respuesta violenta a los abusos (fiscales y personales) que padecían sus habitantes, soberana (e hijas) incluidas. La viuda de Prasutagus aglutina en su lucha por la liber$\operatorname{tad}^{48}$ a trinovantes e icenos, en un levantamiento que está a punto de arrojar a los romanos de la isla. Al final, C. Suetonio Paulino salva la situación con arrojo y disciplina. Años más tarde, en el 66 d. C., estalla la revuelta en Judea, consecuencia última de las corruptelas y pésima gestión de los procuradores romanos (especialmente del último de todos ellos, Gesio Floro). Así, en la década de los años sesenta, nuevos problemas periféricos volvían a crear inestabilidad en un reinado en el que su máxima autoridad (al igual que ocurriera anteriormente con Calígula) volvía a incurrir en parecidos errores.

Uno de los asuntos más importantes fue la «cuestión armenia», problema que centró los esfuerzos de la política exterior romana entre los años 55 al 66 d. C. Tuvo como gran protagonista indiscutible al malogrado Cneo Domicio Cor-

44 Suet., Calígula, 44 y 46. Quizá el escenario fuera la Germania Inferior: Tac., Hist., IV, 15 y D. Cass., LIX, 21, 3. Para un interpretación más ajustada de tales hechos: Anthony A. Barrett, Calígula, Vidas de los césares, Anthony A. Barrett, ed., Barcelona, 2009, 128-131.

45 R. F. Martín, Los doce Césares. Del mito a la realidad, Madrid, 1998, 173 y ss. M. Moro Ipola, «Violencia y maltrato en la familia romana y sus consecuencias: la adolescencia perdida de Tiberio Claudio», ETF, Serie II, Historia Antigua, 21, 2008, 275-285.

46 J.M. Roldán,, Césares, Madrid, 2008, 233-301.

47 Aulo Plaucio Silvano (y a sus órdenes el futuro emperador Vespasiano) y tres legiones (legiones Il Augusta, XIV Gemina y XX Valeria Victrix), un total de 40.000 hombres emprende la ocupación del suroeste de la isla.

48 D. Cass., LXII, 4, 3.

49 Cn Domitius Corbulo: RE, V-1, 1425-1426. Legado, con Claudio, en Germania Inferior había combatido a frisones (Tac., Ann., XI, 19, 1-2) y caucos. El propio emperador le obliga a retornar (aunque le otorga los ornamenta thriumphalia). Con Nerón, al mando de cuatro legiones, recibe la legatura imperial de Galacia y Capadocia con el objetivo de conservar Armenia. Debe compartir el mando con el legado de Siria, C. Umidio Durmio Cuadrado, con el que no se entiende bien. Al ser expulsado el dirigente prorromano Radamisto, Vologeses, rey de los partos, había aprovechado la ocasión para colocar en el trono armenio a su hermano Tiridates. En el año 58 d. C. estalla la guerra: la capital, Artáxata, es destruida, y al año siguiente (59 d. C.) Corbulón penetra hasta la segunda capital de Armenia Triganocerta, que capitula. El plan de Corbulón era convertir Armenia en provincia pero Nerón decide seguir con la política de protectorados. Así coloca en el trono a Tigranes (V), un bisnieto de Herodes el Grande. El nuevo soberano, que había sido educado en Roma, debe abandonar Armenia ante la nueva ofensiva de Tiridates y Vologeses. A ello se añade el fracaso del inexperto L. Cesenio Peto, nuevo gobernador de Capadocia, asediado cerca de Rhandeia y a quien Corbulón no puede socorrer a tiempo. Tal circunstancia obliga a iniciar negociaciones aunque los partos no consigan afianzarse totalmente y se vean, a su vez, obligados a evacuar Armenia (62 d. C.). Nuevamente Corbulón dirige las operaciones militares, previa concentración de un importante contingente de tropas en Melitene (Capadocia). Seguidamente invade Armenia y 
bulón ${ }^{49}$, a quien el emperador, receloso en todo momento de su general, no permitió que llevara a buen término una tarea brillantemente iniciada. El reinado de Nerón concluye con la llamada a la insurrección por parte de C. Iulius Vindex, propretor de la Galia Lugdunense, abriéndose así definitivamente la espita de la "crisis neroniana». Ahora, un grave problema interno, al que seguiría el año de los cuatro emperadores (69 d. C.), impedía cualquier tipo de aventura expansiva y, además, obligaba tanto a salir del profundo bache interno como, forzosamente, a encauzar definitivamente el problema judío (años 70-74 d. C., con los asedios de la capital, Jerusalén y de la fortaleza de Masadá, cercana al mar Muerto).

Tras las turbulencias del año 69 d. C. habrá que esperar a la emergencia de la figura de Vespasiano, futuro purpurado. Una circunstancia concreta catapulta a este militar experimentado a primer plano: La revuelta judía que estalla en el $66 \mathrm{~d}$. C. Y este hecho le exime de correr riesgos o de seguir un futuro incierto como el de Corbulón (obligado a suicidarse por Nerón al haber participado su yerno, Vinucio, en una conjura contra el emperador). Vespasiano y sus hijos, si no expanden sustancialmente el territorio, por lo menos consolidan la autoridad imperial y ponen fin momentáneamente al problema judío, hasta que éste vuelva a recrudecerse en el marco de la política de Adriano ${ }^{50}$.

Con los flavios se asiste a una remodelación del ejército con un total de veintinueve legiones ${ }^{51}$, a la par que se configura un sistema estratégico basado en el limes fortificado, abandonándose paulatinamente el sistema de estados-tapón ${ }^{52}$ (como el caso armenio ya visto y que había dado escaso resultado). Efectivamente, el sistema defensivo de fronteras durante la dinastía Julio-Claudia se había apoyado en fuerzas móviles y en la fidelidad de estados-clientes. El que se irá configurando con la dinastía Flavia y, especialmente, en el siglo II d. C. (bajo los emperadores adoptivos) constituye una clara herencia del anterior, si bien presentará un aspecto más sólido, consolidado y defensivo. El problema principal, no obstante, estuvo en las dificultades de tipo financiero para mantener sine die un ejército profesional de tal envergadura (legiones y cuerpos auxiliares). El hecho de vigilar y controlar unos límites tan dilatados (de unos $10.000 \mathrm{~km}$.) con sectores amplísimos

obliga a Tiridates a rendir obediencia, ante todo el ejército romano al completo, frente a una estatua de Nerón. El mismo 66 d. C. Tiridates acude a Roma y ante Nerón en Nápoles le rinde honores (prosquínesis). En Roma se escenifica todo de nuevo: Tiridates y su séquito repiten la ceremonia ante Nerón. Pero aquella escenografía no llegaba a mostrar, ni mucho menos una victoria decisiva, hasta el punto de que Armenia seguía siendo un deficiente estado-tapón frente a los arsácidas. Vid., J. Le Gall y M. Le Glay, El imperio romano. El alto imperio desde la batalla de Actium hasta la muerte de Severo Alejandro (31 a. C.-235 d. C.), Madrid, 1995, 179-181. J.M. Roldán, J.Ma Blázquez y A. del Castillo, Historia de Roma, II, El Imperio Romano (siglos I-III), Madrid, 1989, 168-170.

50 Que vuele a recrudecerse con la revuelta de Bar Kokhba: B. Isaac, «La política religiosa de Adriano y la segunda revuelta judía», Juan Manuel Corté Copete y Elena Muñiz Gijalvo (Eds.), Adriano Avgvsto, Sevilla, 2004, 141-151.

51 E. Pitillas Salañer, Roma. La forja de un imperio, Zaragoza, 2010. Vid., diagrama, 150.

52 J. Le Gall y M. Le Glay, El imperio romano. El alto imperio desde la batalla de Actium hasta la muerte de Severo Alejandro (31 a. C.-235 d. C.), Madrid, 1995, 319. 
(el limes renano de unos $600 \mathrm{~km}$. y el danubiano, mucho más extenso, en torno a los 2700 ) hacía imposible una defensa lineal continuada ${ }^{53}$.

La llegada de Vespasiano al trono supone la reanudación del avance militar en Britania: Q. Petillius Cerialis combate a los brigantes y su sucesor S. Iulius Frontinus ${ }^{54}$ lucha contra los silures. La definitiva conquista de Gales tiene lugar entre los años 74 al 77/78 d. C. Gneus Iulius Agrícola, suegro de Tácito, se hace cargo del mando en el 78 d. C. Ocupa definitivamente la isla de Mona (Anglesey) ${ }^{55}$ y lleva a cabo una importante campaña contra Calgacus, caudillo de los caledonii, al que derrota al pie del mons Graupius ${ }^{56}$. La construcción del vallum Hadriani, desde la desembocadura del Tyne hasta el golfo de Solway (122-127 d. C.), y el efímero intento del otro muro levantado posteriormente (142 d. C.) y más al norte, en época de Antonino Pío, abandonado a los pocos años, muestra la necesidad de contener, mediante una sistema defensivo (a lo Maginot) a los inquietos caledonii. La construcción de tal defensa suponía la renuncia a la expansión, un nuevo reconocimiento de la necesidad de establecer, tanto para los que estaban dentro como para los situados al otro lado, un límite claro y perceptible.

Las política exterior de época de Domiciano ${ }^{57}$ (81-96 d. C.) contempla la frontera renana con especial interés. La constitución de los Agri Decumates, la creación de dos provincias imperiales consulares (Germania Superior e Inferior) y todo el entramado legionario (ocho legiones), configura un cinturón defensivo cada vez más consolidado. La otra frontera, la danubiana, dispone de fuerzas algo inferiores (cinco legiones) y es precisamente aquí donde Domiciano comienza a sufrir contratiempos. En el 85-86 d. C. los dacios penetran en Moesia y el legado $C$. Oppius Sabinus pierde la vida. Las dificultades militares obligan a dividirla en dos provincias: Mesia Superior e Inferior. Una serie de legados (M. Cornelius Nigrinus Curiatius Maternus ${ }^{58}$, L. Funisulanus Vettonianus, el prefecto pretoriano Cornelius Fuscus [éste, al frente de la legio $V$ Alauda, será derrotado], combaten por aquellos años a los dacios). En el año 88 d. C. L. Tettius Iulianus, gobernador de Mesia Superior, obtiene una victoria sobre los bárbaros en Tapae, pero no mucho después, en el 92 d. C., la legio XXI Rapax es masacrada por los sarmatae iazyges. Esta situación fuerza al emperador a firmar una paz ignominiosa (89 d. C.) con Decébalo, caudillo de los dacios ${ }^{59}$. Se trata de una acuerdo poco usual para la uni-

53 E. Pitillas Salañer, «Algunas cuestiones en torno a la defensa del Imperio [etapa altoimperial hasta el reinado de Septimio Severo]», Scripta Antiqua in honorem Ángel Montenegro Duque et José María Blázquez Martínez, Santos Crespo Ortiz de Zárate y Ángeles Alonso Ávila [Coordinadores \& Editores], Valladolid, 2002, 407-416.

54 Curator aquarum de época de Nerva y autor de una obra sobre los acueductos de Roma (De aquaeductu Urbis Romae) escrita en el $97 / 98$ d. C.

55 C. Suetonio Paulino la había tenido que abandonar al estallar la revuelta de Boudicca.

56 Tac., Agric., 29, 2-4; 30-38.

57 Tito, el que en otro tiempo asediara y ocupara Jerusalén (70 d. C.), había fallecido el 13 de septiembre del $81 \mathrm{~d}$. C.

58 General de Domiciano y posible rival de Trajano al trono imperial, un capax imperii.

59 Caudillo de los dacios (dacii). Adquiere renombre al llegar a un acuerdo — muy favorable, para su pueblo- con el emperador Domiciano (81-96 d. C.). Hacia los años 85-86 d. C., los dacios habían atravesado el Danubio penetrando en Moesia, donde el legado romano C. Oppius Sabinus pierde la vida. En 
lateral diplomacia romana, especialmente porque supuso además ayuda económica y aporte de personal técnico cualificado, lo que paradójicamente permitiría al dacio rebelde preparar su nueva ofensiva.

Esta situación no entra en vías de solución definitiva hasta la llegada al trono de Trajano60, sucesor de Nerva desde el 98 d. C. A una primera campaña (101-102 d. C.) que, de momento, se paraliza con una paz de compromiso solicitada por Decébalo ${ }^{61}$, sigue una segunda y definitiva, con la declaración formal de guerra por parte del Senado y la marcha del emperador desde Roma (4-IV-105 d. C.). Trajano está firmemente decidido a ocupar y anexionar Dacia, y así lo hace cuando la capital, Sarmizegetusa, cae en manos de las tropas romanas. El soberano dacio se sucida ${ }^{62}$ en el momento en el que iba a ser cogido prisionero ${ }^{63}$. Dacia es incorporada con rango de provincia y se funda la nueva Colonia Ulpia Traiana Sarmizegetusa. La columna de Trajano ${ }^{64}$ recoge visualmente aquellas campañas.

el año 87 C. Fuscus, prefecto pretoriano, sufre también un importante contratiempo frente al caudillo dacio. Al año siguiente, $L$. Tettius Iulianus, gobernador de Moesia (Superior), obtiene una importante victoria en Tapae (entrada de la Puerta de Hierro, valle de Bistria). La práctica aniquilación de la legio XXI Rapax, a manos de los sármatas iazyges (92 d. C.), fuerza a Domiciano a firmar una paz vergonzosa. En ella, el emperador se comprometía a aportar ayuda económica y personal militar cualificado con lo que, paradójica e imprudentemente, estaba dando alas a la creciente belicosidad del caudillo dacio. El año $89 \mathrm{~d}$. C. se firma una paz fallida, simple compás de espera hasta que Trajano, a partir del 98 d. C., renueva, en dos guerras sucesivas, la lucha contra Decébalo. En Viminacium el emperador concentra un importante contingente de tropas (once legiones) y se apresta, seguidamente, a la conquista y ocupación de la Dacia. La 1ª Guerra (101-102 d. C.) supone ya, para el caudillo indígena,, un seria advertencia. Las tropas de Trajano, en dos columnas, se adentran en territorio dacio. Trajano, al frente de una de ellas, desde Lederata, atraviesa el Danubio por medio de un puente de pontones. El caudillo dacio intenta ganar tiempo iniciando un proceso de negociaciones que le lleva a entregar una buena parte de la ayuda anteriormente recibida, mientras Trajano prosigue su avance (y ocupación de fortines). Debe finalmente aceptar la presencia de tropas romanas en la capital (Sarmizegetusa). Una nueva violación de los acuerdos (Decébalo mantiene su desafío reuniendo armas, acogiendo desertores y reparando fortificaciones) obliga a Trajano a intervenir. El emperador parte nuevamente de Roma (4 de junio del 105 d. C.), iniciándose así la definitiva destrucción del reino dacio ( $2^{\text {a }}$ Guerra, 105-106 d. C.). Sobre el Danubio, Apolodoro de Damasco (el célebre ingeniero de Trajano) erige un puente de piedra (D. Cass., LXVIII, 13) por donde atraviesa el ejército de invasión. El conflicto adquiere dimensiones de guerra total (exterminio de la población civil). La ajustada maquinaria militar romana (legiones, cuerpos auxiliares, empleo de catapultas para flechas móvil [carroballistae]) va sometiendo el teritorio dacio de forma sistemática. Las tácticas dilatorias de Decébalo (intenta atentar contra el emperador, captura a Casio Longino, comandante de las tropas romanas en Dacia, para chantajear al emperador...) no obtienen resultado. La capital (Sarmizegetusa) cae nuevamente en manos romanas. Decébalo, perseguido de cerca, en el momento en el que iba a ser capturado por un oficial de caballería (Tiberius Claudius Maximus) [M. Speidel], se suicida (escena 108, columna de Trajano). La cabeza del soberano dacio es llevada a Roma (D. Cass., LXVIII, 14). La guerra termina en el 106 d. C. Los tesoros del caudillo dacio («el oro de los dacios") son escondidos bajo el lecho de un río (Sargentia), cuyo curso es desviado para preservar las enormes riquezas acumuladas (165.000 kilos de oro y 331.000 de plata, según J. Carcopino). Finalmente serán descubiertos por los romanos y empleados en la erección del foro de Trajano en Roma.

60 E. Cizek, L époque de Trajan, Bucarest-París, 1983. J.Bennett, Trajan. Optimus Princeps, London-N.York, 1997. J.Mª Blázquez, Trajano, Barcelona, 2003. VV.AA., Trajano, Jaime Alvar y José Mª Blázquez (Eds.), Madrid, 2003.

61 D. Cass., LXVIII, 9, 1 y 4-5.

62 D. Cass., LXVIII, 14.

63 M. Speidel, «The Captor of Decebalus. A new inscription from Philippi», JRS, LX, 1970, lam. XIIIXIV, 141-142.

64 J.Mª Blázquez, «Las res gestae de Trajano militar. Las guerras dácicas», Aqvila Legionis, 6, 2005, 19-55. 
De esta forma, con Trajano, se llega a la culminación, en esta parte del Imperio, de una expansión iniciada en época republicana y que, desde Augusto, como hemos visto a grandes rasgos, atravesó por contratiempos diversos.

La conquista en determinados momentos debía detenerse para cobrar así nuevo impulso. Con Trajano (que vuelve gravemente enfermo de su posterior campaña en Oriente) y su sucesor, Adriano (que al igual que Tiberio, buen general en su juventud, cuando ocupa el trono decide mantener lo conquistado, a la par que administra y viaja por el Imperio...) se asiste al momento culminante de un ya largo proceso que parece entrar en una fase de agotamiento.

En la época altoimperial no existió un plan imperialista trazado de antemano. Por el contrario, la política expansiva y de posterior contención de lo conquistado, actuó en función de cada circunstancia, teniendo en cuenta la actividad (o falta de ella) del emperador de turno, pero observando que a un determinado sobreesfuerzo seguían, casi necesariamente, posteriores años de respiro y recuperación. La expansión parecía mostrar unos límites y éstos no podían ser otros que la propia capacidad expansiva e integradora del Imperio, reflejo de cada momento puntual. La advertencia a Druso presentaba una doble lectura. Era un intento por frenar al conquistador (por parte del que se resistía a ser conquistado) pero, a su vez, era una llamada de atención al ocupante romano (sobre potenciales y futuros peligros, como la derrota de Varo en Teutoburgo) y, por qué no decirlo, podía servir - a su vez- de «mecanismo de reflexión» sobre los límites efectivos del poder, sujeto a sus reales posibilidades expansivas, según momentos y circunstancias. Resultaba obligado (?), por lo tanto, aprender la lección. 
